Research Article

\title{
Contribution of River Mouth Reach to Sediment Load of the Yangtze River
}

\author{
C. Wang, ${ }^{1,2}$ S. B. Dai, ${ }^{2}$ L. S. Ran, ${ }^{3}$ L. Jiang, ${ }^{2}$ and W. T. Li ${ }^{2}$ \\ ${ }^{1}$ State Key Laboratory of Soil Erosion and Dry Land Farming on the Loess Plateau, Institute of Water and Soil Conservation, \\ Chinese Academy of Sciences and Ministry of Water Resources, Yangling, Shaanxi 712100, China \\ ${ }^{2}$ Anhui Center for Collaborative Innovation in Geographical Information Integration and Application, Chuzhou University, \\ Fengle Road 1528, Chuzhou, Anhui 239012, China \\ ${ }^{3}$ Department of Geography, National University of Singapore, 10 Kent Ridge Crescent, Singapore 119260
}

Correspondence should be addressed to S. B. Dai; shibaodai@163.com

Received 4 February 2015; Revised 9 April 2015; Accepted 21 April 2015

Academic Editor: Steffen Mischke

Copyright (C) 2015 C. Wang et al. This is an open access article distributed under the Creative Commons Attribution License, which permits unrestricted use, distribution, and reproduction in any medium, provided the original work is properly cited.

\begin{abstract}
This paper examined the sediment gain and loss in the river mouth reach of the Yangtze River by considering sediment load from the local tributaries, erosion/accretion of the river course, impacts of sand mining, and water extraction. A quantitative estimation of the contribution of the river mouth reach to the sediment load of the Yangtze River was conducted before and after impoundment of the Three Gorges Dam (TGD) in 2003. The results showed that a net sediment load loss of 1.78 million ton/yr (Mt/yr) occurred from 1965 to 2002 in the study area. The contribution of this reach to the sediment discharge into the sea is not as high as what was expected before the TGD. With impoundment of the TGD, channel deposition (29.90 Mt/yr) and a net sediment loss of $30.89 \mathrm{Mt} / \mathrm{yr}$ occurred in the river mouth reach from 2003 to 2012. The river mouth reach has acted as a sink but not a source of sediment since impoundment of the TGD, which has exacerbated the decrease in sediment load. Technologies should be advanced to measure changes in river channel morphology, as well as in water and sediment discharges at the river mouth reach.
\end{abstract}

\section{Introduction}

Over the past several decades, riverine sediment issues have received a great deal of attention worldwide because of the importance of sediment transport in fluvial systems $[1,2]$, as well as increasing anthropogenic impacts, such as construction of the Three Gorges Dam (TGD) in the Yangtze River (or Changjiang in Chinese) basin [3]. Many rivers have experienced decreasing sediment loads, triggering bank collapses and channel erosion in their deltas $[4,5]$. Sediment load in the Yangtze River has decreased sharply since the 1950s, due largely to dam construction $[2,6,7]$. This has led to serious river management problems, such as channel erosion and delta retreat $[2,6,8]$. Additionally, undercutting of the river channel has reduced the water level and depleted water resources in the dry season [9]. Delta erosion has hampered expansion of the shoreline and government land exploitation projects in Shanghai, the largest city in China. The world's largest dam (the TGD) was put into operation on the river in
2003. Since then, more than $70 \%$ of the sediment $[6,10]$ that previously passed through the dam site has been sequestered. Sediment starvation of the downstream waters has had serious impacts, including undercutting of the river channel bed and bank failures. Because of the large-scale human activities within the watershed, the Yangtze River provides a valuable opportunity to evaluate the responses of a river system to natural and anthropogenic impacts.

Though many studies have been conducted to investigate sediment in the Yangtze River, little attention has been given to the lower reaches, especially below Datong station. Sediment load at Datong station (located at the tidal limit, $624 \mathrm{~km}$ upstream of the river mouth) is generally taken as the sediment flux that is discharged into the ocean from the Yangtze River $[6,10]$ since there is no gauging station on the river trunk below. Sediment export in the river mouth reach (from Datong station to the estuary) remains largely unknown to researchers, partly because of the complex impacts of tides. Previous studies have shown that the main channel and 
connected lakes have great potential to regulate sediment transport processes of the Yangtze River [11]. Hence, the river mouth reach might also play an important role in its sediment budget in the context of sediment deficiency after closure of the TGD. This is for several reasons; namely, (a) the river mouth reach extends $624 \mathrm{~km}$ from Datong station to the sea, comprising one-tenth of the total length of the Yangtze River. The channel width in this reach varies from 1 to $10 \mathrm{~km}$, which provides the potential to regulate sediment discharge from the upper reaches [11]; (b) the local drainage area in this reach is about $0.1 \times 10^{6} \mathrm{~km}^{2} \quad(\approx 6 \%$ of the total drainage area of the Yangtze River basin); accordingly, sediment supply from this area cannot be neglected; (c) the Huaihe River (a large river located in the northern part of the Yangtze River basin) joins the Yangtze River in this reach. Accordingly, sediment supply from the Huaihe River might play an important role in mitigating the sediment deficiency of the Yangtze River; (d) finally, intensified anthropogenic activities, such as sand mining and water diversion, may have substantial impacts on the sediment processes.

Taking the above factors into account, sediment discharge into the sea from the Yangtze River would be quite different from that gauged at Datong station. Since less sediment has been discharged into the river mouth in recent years, sediment supply from this local reach might play an increasingly important role in maintenance of sediment balance in this reach and coastal areas. An exact evaluation of the quantity of sediment discharged into the sea will be beneficial to both scientific research and government engineering projection. Furthermore, since many of the lowest gauging stations on rivers worldwide are located at a distance from the river mouths, investigation of the buffering function of the river mouth reaches is essential for proper determination of variations in riverine sediment flux to the sea and understanding the landsea interaction. Accordingly, the results presented herein will be useful to studies of other similar rivers.

In this study, a quantitative evaluation of sediment discharge into the sea was conducted using the sediment budget method. The specific goals of the study were to (a) evaluate sediment supply from local tributaries and the Huaihe River in the river mouth reach, (b) examine the erosion/accretion of the river course, including the impacts of sand mining, (c) evaluate sediment losses because of water extraction, and (d) establish a sediment budget for this reach and evaluate how much sediment is discharged into the sea, especially after closure of the TGD.

\section{Physical Setting}

The Yangtze River originates from the Qinghai-Tibetan Plateau at an elevation of $5100 \mathrm{~m}$ and runs east for $6300 \mathrm{~km}$ to the East China Sea (Figure 1). The main source of sediment in the Yangtze River is the lower section of the upper reach, which ends at Yichang (where the TGD is located). Significant sediment deposition occurred in the middle reaches, from Yichang to Hankou [10, 11], before 2003. However, the deposition reach shifted to the upper Yichang following impoundment of the TGD. The channel in the lower reach (from Hankou to Datong) has remained largely in balance in the last few decades, and Datong station is free of tidal influences. Given the difficulty quantifying the effects of tidal impacts on sediment transport, estimating sediment load below Datong is very challenging. Therefore, the observed sediment flux at Datong station is generally regarded as the sediment load into the ocean. The river course below Datong station mainly drains through Anhui and Jiangsu Provinces, and Datong station is located in the middle of Anhui Province. The channel length below Datong station in Anhui Province is $199 \mathrm{~km}$, which is half the total channel length at Anhui Province. The total length from the boundary of Anhui to Jiangyin, which is located at the tidal flow limit in the low flow seasons in Jiangsu Province, is $218 \mathrm{~km}$. Shanghai is located at the mouth of the river. The entire subbasin of the river mouth reach is in the most prosperous area in China, and intensified human impacts of projects such as sand mining and water diversion are widespread.

Several tributaries join the Yangtze River below Datong station, namely, the Yuxi, Qingyijiang, Shuiyangjiang, Chuhe, and Qinhuaihe rivers, and the Lake Taihu system. These tributaries originate from the low hilly areas alongside the trunk river and then drain through the alluvial plain along the Yangtze River (Figure 1). The annual precipitation is $1000-$ $1100 \mathrm{~mm}$ in this local drainage area. The specific soil erosion rate is less than that of the above reaches of the Yangtze River because of the lower relief and better vegetation cover.

The Huaihe River is one of the seven largest rivers in China, with a drainage area of 0.27 million $\mathrm{km}^{2}$. Historically, the Huaihe River was an independent river system that discharged into the Yellow Sea. However, after 1128, the majority of its runoff and sediment load (80\%) was discharged into the Yangtze River through a connective waterway because of the diversion of the Huanghe River [18]. Annually, $22.6 \times 10^{9} \mathrm{~m}^{3}$ and 3.73 million tons $(\mathrm{Mt} / \mathrm{yr})$ of water and sediment were discharged into the Yangtze River from the Huaihe River, respectively, from 1965 to 2005 . Thus, the actual water and sediment load discharged into the river mouth reach is not only from the upper reaches, although runoff and sediment from the Huaihe River are commonly neglected. In the present study, sediment discharge from the Huaihe River was taken into account.

\section{Data and Methods}

The sediment budget method is widely used to examine the sediment transport process in river systems [19]. In this study, a sediment budget was established in the river mouth reach to evaluate its contribution to sediment discharge from the Yangtze River and determine how much sediment is discharged into the sea. Consider

$$
\begin{aligned}
Q_{s_{-} \text {out }}= & Q_{s_{-} \text {upper reach }}+Q_{s_{-} \text {local reach }}+Q_{s_{-} \text {erosion }} \\
& -Q_{s_{-} \text {deposition }}-Q_{s_{-} \text {water extraction }},
\end{aligned}
$$

where $Q_{s_{\text {_out }}}$ is the sediment discharged out of the river course and into the sea, $Q_{s_{-} \text {upper reach }}$ refers to the sediment load from the upper reach, $Q_{s \_ \text {local reach }}$ is sediment load from the local tributaries in the river mouth reach (including the Huaihe 


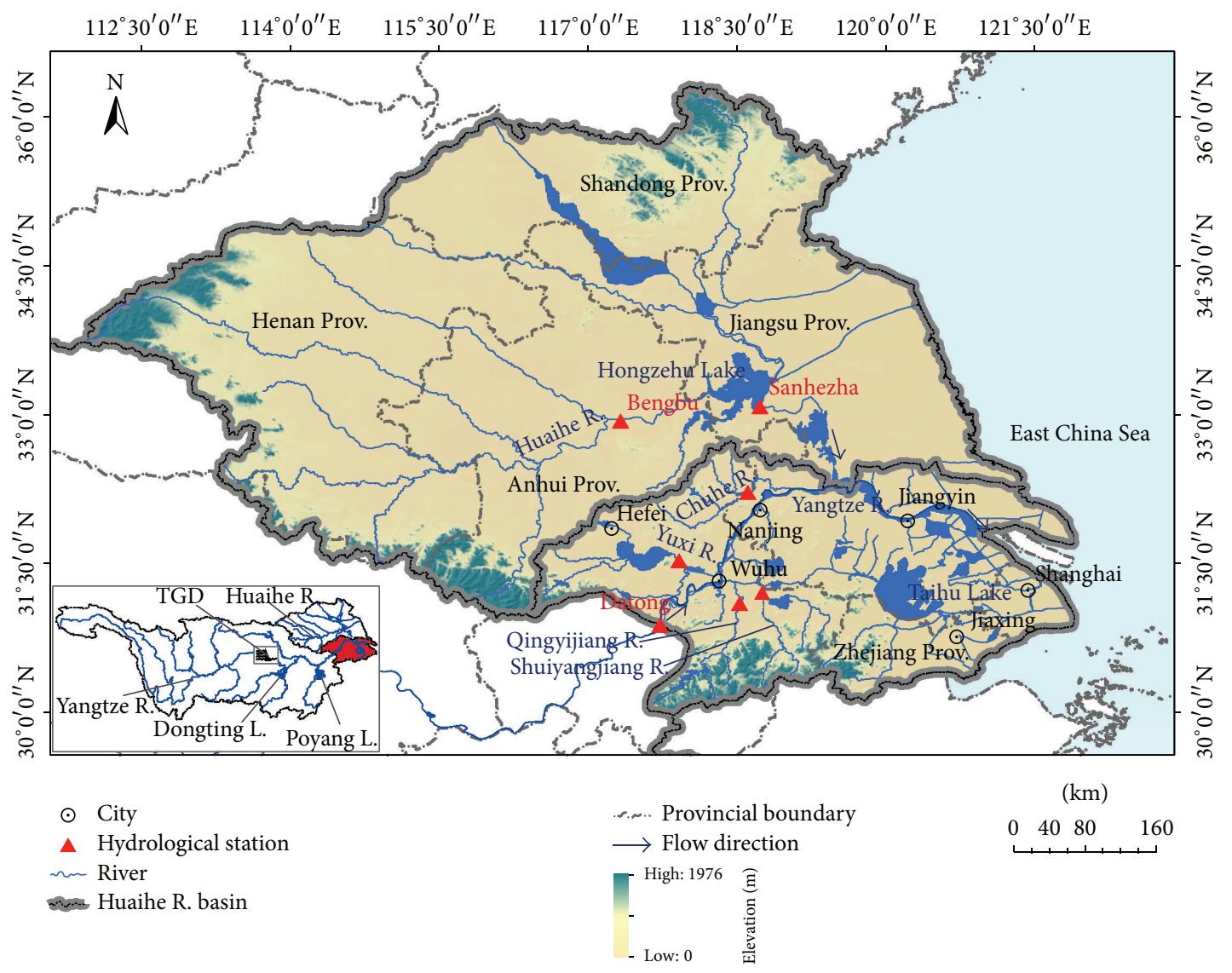

FIgURE 1: Map of the study area.

River), $Q_{s_{-} \text {water extraction }}$ refers to sediment losses because of the water extraction, and $Q_{s_{-} \text {erosion }}$ and $Q_{s_{-} \text {deposition }}$ refer to the sediment eroded from or deposited in the river channel, respectively.

A variety of data sources were collected to build this budget. The annual sediment load at Datong station and some tributaries (such as the Yuxi River, Qingyijiang River, Shuiyangjiang River, and the Chuhe River) from 1965 to 2005 was obtained from the Hydrology Bureau of Anhui Province, which is an affiliate of the Ministry of Water Resources of China (MWRC). The data describing the Huaihe River $[13,14]$ and Taihu Lake system [12] are from previously published material. Channel erosion/accretion data were obtained from Wang et al. [16], Liu [15], and Qu [17], who conducted studies based on relief maps. The data sources of Wang et al. [16] and $\mathrm{Qu}$ [17] are maps published by the Navigation Guarantee Department of Chinese Navy Headquarters, while Liu [15] used data provided by the Bureau of Changjiang River Management of Anhui Province.

The total drainage area of the river mouth reach is 0.1 million $\mathrm{km}^{2}$, while the total drainage area of the Yuxi, Qingyijiang, Shuiyangjiang, and Chuhe rivers is $24,568 \mathrm{~km}^{2}$, and the total drainage area of the Lake Taihu system is $36,895 \mathrm{~km}^{2}$. Thus, there is still an area of about $38,537 \mathrm{~km}^{2}$ that is not gauged or for which gauged data is not available (hereafter referred to as ungauged area). To establish the sediment budget, it is necessary to evaluate sediment yield from this area. Owing to the similarity of the natural conditions of the ungauged area to the Yuxi, Qingyijiang, Shuiyangjiang, and Chuhe rivers, the average specific sediment yield of these four rivers was assigned to the ungauged area.

\section{Results}

4.1. Sediment Supply from the Local Tributaries. The local drainage area of the river mouth reach could be divided into three parts, the area that the four gauged rivers (the Yuxi, Qingyijiang, Shuiyangjiang, and Chuhe rivers) drain through, the area composed of regions that are not gauged or for which gauging data is not available, and the Lake Taihu drainage system. The average sediment load from each area is shown in Table 1, and the temporal variations of the four rivers are shown in Figure 2. The combined sediment from the four rivers was $1.45 \mathrm{Mt} / \mathrm{yr}$ during 1965-2002. The ungauged area was 1.56-fold larger than that of the four rivers. Sediment load from this area was $2.26 \mathrm{Mt} / \mathrm{yr}$, assuming that it has the same specific sediment yield as the basins of the four rivers. The sediment load of the Lake Taihu system was obtained from a study by $\mathrm{Wu}$ [12], who reported that $0.1 \mathrm{Mt} / \mathrm{yr}$ of sediment was discharged from the system in 1954. This was a high flow year in Lake Taihu, and $0.1 \mathrm{Mt} / \mathrm{yr}$ may be among the highest discharges that occurred from 1965 to 2012. 
TABLE 1: Sediment load of the tributaries of the river mouth reach of the Yangtze River.

\begin{tabular}{|c|c|c|c|c|c|}
\hline \multirow{2}{*}{ River } & \multirow{2}{*}{ Station } & \multirow{2}{*}{ Drainage area $\left(\mathrm{km}^{2}\right)$} & \multicolumn{2}{|c|}{ Sediment load (Mt/yr) } & \multirow{2}{*}{ Data source } \\
\hline & & & 1965-2002 & 1996-2005 & \\
\hline Qingyijiang & Xihe & 5796 & 0.36 & 0.23 & MWRC \\
\hline Shuiyangjiang & Xuancheng & 3410 & 0.53 & 0.27 & MWRC $^{*}$ \\
\hline Yuxihe & Chaohuzha & 9258 & 0.38 & 0.18 & MWRC* \\
\hline Chuhe & Chaheji & 6104 & 0.18 & 0.08 & MWRC* \\
\hline Total rivers & & 24,568 & 1.45 & & \\
\hline Taihu Lake & & 36,895 & 0.10 & 0.10 & {$[12]$} \\
\hline Ungauged area & & 38,537 & 2.38 & 1.14 & Estimation in this study \\
\hline Sum & & 100,000 & 3.81 & 2 & \\
\hline Huaihe & Sanhezha & 270,000 & 3.73 & 2.64 & {$[13,14]$} \\
\hline Total & & & 7.54 & 4.65 & \\
\hline
\end{tabular}

${ }^{*}$ MWRC, Ministry of Water Resources of China.

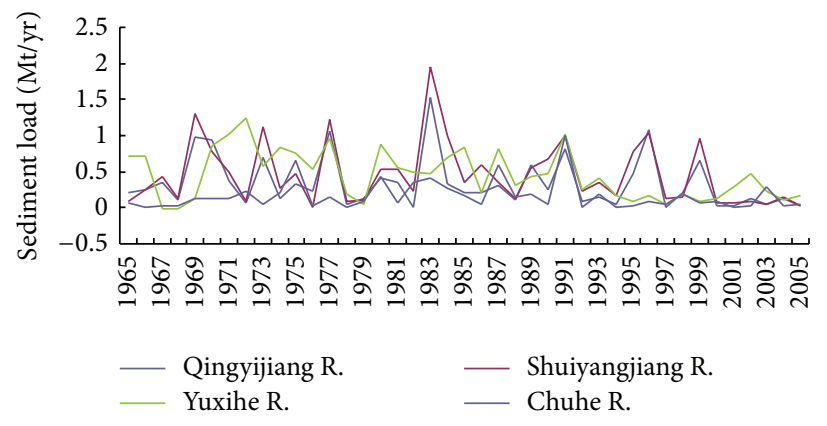

(a)

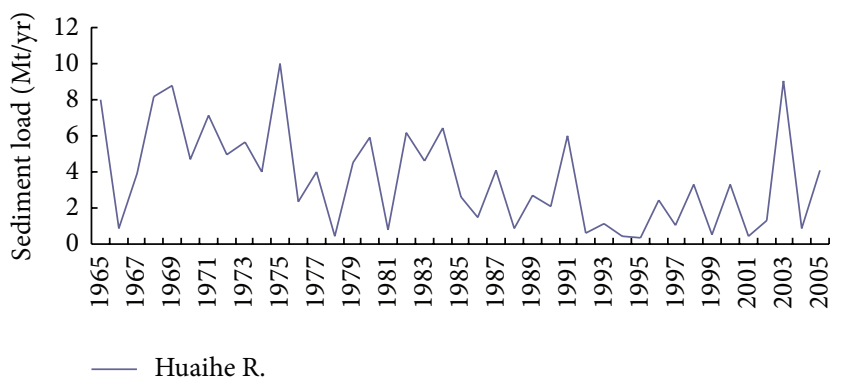

(b)

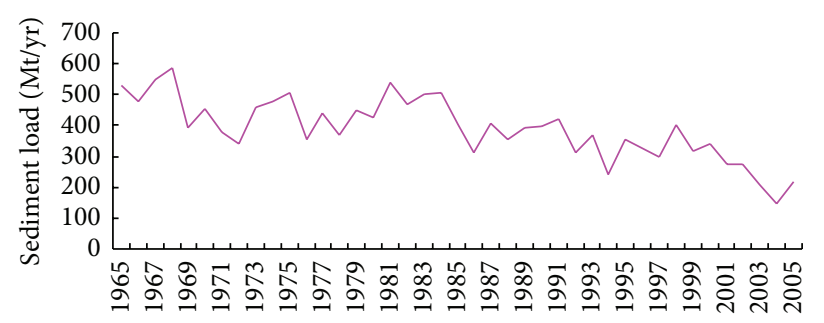

(c)

Figure 2: Variations in sediment load of local tributaries in the river mouth reach, Huaihe River, and Datong station.

Because this was the only data available for the Lake Taihu system, we selected $0.1 \mathrm{Mt} / \mathrm{yr}$ as the sediment load of the Lake Taihu system from 1965 to 2012, even though it was likely an overestimation.

The total sediment load of the local tributaries is $3.81 \mathrm{Mt} / \mathrm{yr}$. As indicated above, the majority of runoff and sediment load ( $80 \%)$ of the Huaihe River is discharged into the Yangtze River through a connective waterway. In this study, the sediment discharge from the Huaihe River was taken into account. Although the Huaihe River has a drainage basin of $270,000 \mathrm{~km}^{2}$, its average specific sediment yield is much less than that of the Yangtze River. Additionally, attenuation by Lake Hongzehu, which is located in the middle of the Huaihe River, results in only $49.9 \%$ of the sediment being discharged from the lake. Of this sediment, $80 \%$
(3.73 Mt/yr) is discharged into the Yangtze River [14]. When combined with that from the local tributaries and the Huaihe River, $7.54 \mathrm{Mt} / \mathrm{yr}$ sediments are discharged into the river mouth reach of the Yangtze River. The average sediment load from the upper reach of the Yangtze River was $400.15 \mathrm{Mt} / \mathrm{yr}$ in 1965-2002; therefore, sediment load from the local tributaries together with the Huaihe River comprises only $1.9 \%$ of that from the upper reach of the Yangtze River. Yang [20] investigated the contribution of water and sediment fluxes to the sea from the subcatchment below Datong station in the Yangtze River (excluding the Huaihe River) based on several estimations. Assuming that the specific sediment yield of the river mouth reach is similar to that of Poyang Lake (above the river mouth reach), Yang [20] estimated that the sediment yield of the river mouth reach would be $11 \mathrm{Mt} / \mathrm{yr}$ in 1956-2010, which 
TABLE 2: Erosion/accretion of the river mouth reach (unit: $\mathrm{Mt} / \mathrm{yr})^{*}$.

\begin{tabular}{|c|c|c|c|c|c|}
\hline \multicolumn{2}{|c|}{ Anhui section [15] } & \multicolumn{2}{|c|}{ Jiangsu section [16] } & \multicolumn{2}{|c|}{ Whole section [17] } \\
\hline Time & Erosion/accretion & Time & Erosion/accretion & Time & Erosion/accretion \\
\hline 1966-1987 & -30.67 & 1970-1985 & 104.66 & & \\
\hline 1987-2002 & -29.12 & 1985-1992 & -196.34 & & \\
\hline 1966-2002 & -30.02 & $1992-2003$ & -78.30 & $1969-2003$ & -1.55 \\
\hline 2002-2007 & 5.34 & $1970-2003$ & 9.01 & & \\
\hline 2007-2012 & 5.95 & & & & \\
\hline 2002-2012 & 5.66 & & & 2003-2008 & 124.33 \\
\hline
\end{tabular}

${ }^{*}$ The original units of the referenced data were $10^{6} \mathrm{~m}^{3} / \mathrm{yr}$, but these were changed to $\mathrm{Mt} / \mathrm{yr}$ for convenience under the assumption that the dry bulk density of the sediments was $1.3 \times 10^{3} \mathrm{~kg} / \mathrm{m}^{3}[6]$.

was $2.9 \%$ of the sediment load of Datong station in the same time interval. Yang [20] suggested that the actual specific sediment yield of the river mouth reach might be higher than that of the Poyang Lake river system due to the better vegetation and large dam interception in the Poyang Lake river system and lower than that of the middle and lower reaches owing to the higher relief and steeper river gradient. Hence, he estimated that the proportion of sediment flux from the river mouth reach to that of the entire basin would be greater than $2.9 \%$, but lower than that of its proportion of water yield $(6.3 \%)$. Specifically, he suggested that the proportion would be $3 \%$ to $4 \%$ [20]. This value was almost double that of the present study. Based on the gauged data, we compared the sediment load of the tributaries in the Poyang Lake river system and local tributaries of the river mouth reach and found that the former was much higher than the later. Accordingly, the results reported by Yang [20] are likely higher than the actual value.

4.2. Erosion/Accretion of the River Channel. Several studies have investigated the erosion/accretion of the river channel below Datong station (Table 2). Liu [15] studied the channel evolution of the Anhui section. They found that the river channel in this section eroded at an average rate of $-30.02 \mathrm{Mt} / \mathrm{yr}$ from 1966 to 2002, while a slight $(5.66 \mathrm{Mt} / \mathrm{yr})$ accretion occurred from 2002 to 2012 (after impoundment of the TGD). Wang et al. [16] studied changes in the channel of Jiangsu Province (from the boundary of Anhui to Jiangyin, hereafter referred to as Jiangsu reach) and found that sediment was deposited at an average rate of $104.66 \mathrm{Mt} / \mathrm{yr}$ from 1970 to 1985 , but that severe erosion occurred from 1985 to 2003 . On average, slight deposition $(9.01 \mathrm{Mt} / \mathrm{yr})$ occurred from 1970 to 2003 in Jiangsu reach. When combined with the results reported by Liu (2013) and Wang et al. [16], the evolution of the river channel from Datong to Jiangyin before impoundment of the TGD in 2003 can be determined, even though the time scale of the two studies does not match exactly. We found that the river channel below Datong underwent moderate ( $-21.01 \mathrm{Mt} / \mathrm{yr}$ ) erosion from 1966 to 2002 . Qu [17] investigated the evolution of the entire reach between Datong and Jiangyin and found that the river channel experienced slight erosion ( $-1.55 \mathrm{Mt} / \mathrm{yr})$ in 1969-2003.

Previous studies indicated that the river channel of the lower reach of the Yangtze River was almost in balance in previous decades [21-23]. Examination of the results of studies conducted by Wang et al. [16], Liu [15], and Qu [17] revealed that, although differences exist, these studies are generally consistent with the results of previous studies of the river channel (slight erosion/accretion) above Datong station before 2003. Since there is no way to tell which results were most likely, we arbitrarily selected the average of the results reported by Liu [15] and Wang et al. (2007) [16] $(-21.01 \mathrm{Mt} / \mathrm{yr})$ and $\mathrm{Qu}[17](-1.55 \mathrm{Mt} / \mathrm{yr})$ as the actual erosion/accretion results before 2003. Hence, we obtained a slight erosion of $-11.28 \mathrm{Mt} / \mathrm{yr}$ for the river channel from Datong to Jiangyin before 2003. The distance from Datong to Jiangyin is $417 \mathrm{~km}$ and the channel width is $1-10 \mathrm{~km}$. Thus, this erosion $(-11.28 \mathrm{Mt} / \mathrm{yr})$ is very small when the entire river course is considered.

After impoundment of the TGD in 2003, sediment transport processes below the dam were quite different from the pre-TGD period. An investigation by Liu indicated that deposition of $5.66 \mathrm{Mt} / \mathrm{yr}$ occurred in the Anhui section in 2002-2012. The Bulletin of River Sediment of China 2008 [24] reported a deposition of $5.79 \mathrm{Mt} / \mathrm{yr}$ from 2001 to 2006 in the Nanjing section $(92.3 \mathrm{~km})$. If the deposition rate at the Nanjing section in 2001-2006 was selected as the deposition rate of the entire Jiangsu section $(218 \mathrm{~km})$ in $2003-2012$, then the total deposition would be $13.67 \mathrm{Mt} / \mathrm{yr}$. Then the deposition in the whole river mouth reach would be $19.33 \mathrm{Mt} / \mathrm{yr}$.

It should be noted that $\mathrm{Qu}$ [17] indicated that a significant deposition $(124.33 \mathrm{Mt} / \mathrm{yr}, 80.9 \%$ of the sediment load at Datong station at the same time) occurred from 2003 to 2008. If these results are accurate, significant deposition would occur in the river channel and a sharp decrease in sediment load would occur in the river mouth reach. However, no studies have reported these issues; therefore, the results reported by Qu should be verified.

\subsection{Sediment Losses because of Water Extraction and Sand Mining}

4.3.1. Water Extraction. Because there is little data available regarding water extraction, its effects on sediment flux in the Yangtze River are still not fully understood. Zhang and Chen [25] reported that, in a typical dry year of 1978 , the total water extraction below Datong station was $32.1 \times 10^{9} \mathrm{~m}^{3} / \mathrm{yr}$. In 1995, about $20.4 \times 10^{9} \mathrm{~m}^{3} / \mathrm{yr}$ water was extracted from the Yangtze River in Jiangsu Province alone. Because water extraction increased greatly from the 1970s, they estimated that the total 
water extraction below Datong station would reach $800 \mathrm{~m}^{3} / \mathrm{s}$, or $2.8 \%$ of the average water discharge at Datong $(896.4 \times$ $10^{9} \mathrm{~m}^{3} / \mathrm{yr}$ ), in 1950-2010. In the present study, we assumed that the water extraction before 2000 was half that after 2000 , and the suspended sediment concentration of the extracted water was the same as that of the Datong station. Accordingly, $1.4 \%$ and $2.8 \%$ of the sediment load at Datong, which was $5.6 \mathrm{Mt} / \mathrm{yr}$ and $4.41 \mathrm{Mt} / \mathrm{yr}$, respectively, were lost because of water extraction before and after 2000 .

4.3.2. Sand Mining. Sand mining is frequently mentioned when addressing the factors that impact sediment load [6, $10,26]$. Although some researchers have suggested that sand extraction may have had a significant impact on sediment load [26], an in situ study indicated that the infilling of an excavation pit was mainly the result of erosion from nearby sites $[27,28]$, but not from the settlement of the suspended load. The previous experimental study implied that sand mining $[27,28]$ could effectively shape the river channel, but would have limited direct impact on the suspended sediment load $[29,30]$.

Since sand mining could substantially shape the river channel, its impacts on changes in morphology calculated by the relief maps (as conducted by Wang et al. [16], Liu [15], and $\mathrm{Qu}$ [17]) would be significant. Relief maps in different stages can directly indicate the evolution of the river channel, and consequently the sediment load change. When considering the contribution of sand mining, the actual sediment load change calculated by the relief maps should be subtracted from the volume of the sand mined.

To date, no overall investigation of sand mining in the Yangtze River basin has been conducted. It has been reported that, in Anhui Province, sand extraction from the stem channel of the Yangtze River increased from $7 \mathrm{Mt} / \mathrm{yr}$ at the beginning of the 1990s to $15 \mathrm{Mt} / \mathrm{yr}$ at the end of the 1990s [15]. Since the total length of the river channel at Anhui Province $(400 \mathrm{~km})$ is almost equal to that of the study area $(417 \mathrm{~km})$, we assumed that the amount of sand extracted from the study area was equal to that removed from Anhui Province (15 Mt/yr) before 2003.

To reduce and legalize sand mining activities in the Yangtze River, the government issued the "Regulations of management of sand mining in the Yangtze River" in 2001. Under these regulations, the authorized quantity of sand mining in the Anhui Province section for 2004-2010 was $15.54 \mathrm{Mt} / \mathrm{yr}$ [15], while it was 5.6 Mt/yr in the Jiangsu Province section. Considering that the river length of the studied area of the present paper $(417 \mathrm{~km})$ is $53 \%$ of that of the total length of the river channel in Anhui and Jiangsu Provinces $(780 \mathrm{~km})$, sand extraction from the study area will be $10.57 \mathrm{Mt} / \mathrm{yr}$ in 2004-2010, excluding illegal mining. Herein, the authorized quantity of sand mining ( $10.57 \mathrm{Mt} / \mathrm{yr})$ in 2004-2010 was taken as the actual volume of sand mining after 2003.

\subsection{Sediment Discharge into the Sea by the Yangtze River before and after Impoundment of the TGD}

4.4.1. Preimpoundment Sediment Budget. The quantity of sediment load released out of the river mouth reach was determined by the gains and losses of the sediment in the river channel. The gains included sediment from the upper reach, local reach, and erosion of the river bed. The losses included sediment deposition and water extraction (for uses such as agriculture, industrial use, and domestic consumption). As discussed above, sand mining could substantially shape the river channel and have impacts on the changes in morphology calculated by the relief maps. When constructing the sediment budget, the contribution of the erosion/accretion calculated by the relief maps should subtract the volume of sand mined. We estimated that the sand extracted from the study area before 2002 was $15 \mathrm{Mt} / \mathrm{yr}$; hence, the $Q_{s_{-} \text {deposition }}$ should be $3.72 \mathrm{Mt} / \mathrm{yr}(15 \mathrm{Mt} / \mathrm{yr}-11.28 \mathrm{Mt} / \mathrm{yr})$. These findings indicate that the erosion calculated by the relief maps is lower than that of the volume of sand mining, implying that slight deposition must have occurred (3.72 Mt/yr).

Based on the discussion above, we established the sediment budget in the river mouth reach for the pre- and postTGD periods, respectively. The sediment budget in 1965-2002 was as follows (units, Mt/yr):

$$
\begin{aligned}
Q_{s_{-} \text {out }}(398.37)= & Q_{s_{-} \text {upper reach }}(400.15) \\
& +Q_{s \_ \text {local reach }}(7.54) \\
& -Q_{s_{-} \text {deposition }}(3.72) \\
& -Q_{s \_ \text {water extraction }}(5.6)
\end{aligned}
$$

The combined sediment load loss was $9.32 \mathrm{Mt} / \mathrm{yr}$, while the sediment gain was 7.54 in the river mouth reach, indicating that there was a net loss of $1.78 \mathrm{Mt} / \mathrm{yr}$ before impoundment. The sediment loss $(1.78 \mathrm{Mt} / \mathrm{yr})$ was only $0.44 \%$ of the sediment load at Datong at the same time $(400.15 \mathrm{Mt} / \mathrm{yr})$. Therefore, the contribution of the river mouth reach to the total sediment discharge into the sea was minimal before 2003.

4.4.2. Sediment Budget after 2003. To match the time scale (2002-2012) of the present study, it was necessary to estimate the sediment load of the local tributaries and the Huaihe River over the same time period because only the times series data before 2005 was available for these rivers. Evaluation of the annual sediment load of the local tributaries and the Huaihe River from 1965-2005 revealed that sediment load of these rivers showed a decreasing trend during this time interval. In the present study, we took the average sediment load of the local tributaries and the Huaihe River from the time period of 1996-2005 (3.42 Mt/yr) as the sediment load during 2002-2012.

As indicated above, the total deposition in the study area was $19.33 \mathrm{Mt} / \mathrm{yr}$ in 2003-2012, while the amount of sand mining was $10.57 \mathrm{Mt} / \mathrm{yr}$ during the same period. When sand mining was considered, the actual sediment deposition (loss) was $29.90 \mathrm{Mt} / \mathrm{yr}$. Additionally, water extraction was responsible for $2.8 \%(4.41 \mathrm{Mt} / \mathrm{yr})$ of the sediment load at Datong station 
(145.06 Mt/yr) in 2003-2012. We used these data to construct the sediment budget for 2003-2012 (unit: Mt/yr). Consider

$$
\begin{aligned}
Q_{s_{\text {_out }}}(114.17)= & Q_{s_{-} \text {upper reach }}(145.06) \\
& +Q_{s_{-} \text {local reach }}(3.42) \\
& -Q_{s_{-} \text {depostition }}(29.90) \\
& -Q_{s_{\text {_water extraction }}}(4.41) .
\end{aligned}
$$

The combined sediment loss was $34.31 \mathrm{Mt} / \mathrm{yr}$, while the sediment gain was $3.42 \mathrm{Mt} / \mathrm{yr}$ in the river mouth reach, indicating that a net loss of $30.89 \mathrm{Mt} / \mathrm{yr}$ occurred after the TGD. The sediment loss (30.89 Mt/yr) was about $21.3 \%$ of the sediment load at Datong during the same period (145.06 Mt/yr).

Examination of the sediment budget for the two periods revealed that sediment load decreased sharply in the river mouth reach from $398.37 \mathrm{Mt} / \mathrm{yr}$ in 1965-2002 to $114.17 \mathrm{Mt} / \mathrm{yr}$ in 2003-2012 after impoundment of the TGD. In both periods, deposition occurred in the river mouth reach, especially after impoundment of the TGD, which indicated that downstream sediment recovery was limited to the middle and lower reaches.

\section{Discussion}

5.1. Regulation Effects of the River Mouth Reach on Sediment Load. It has been suggested that the buffering function of river mouth reaches plays an important role in regulation of the sediment processes. In the present study, we examined the sediment gain and loss based on gauged data together with estimated values and found that the river mouth reach did not strongly influence sediment discharge into the sea from the Yangtze River before the impoundment of the TGD. Evaluation of the role that each impact factor could play in regulation of the sediment budget in the river mouth reach revealed the following: (a) The sediment yield in the river mouth reach is very low relative to that of the middle and upper reaches. The proportion of the drainage area of the river mouth reach to the entire basin is comparatively small. Accordingly, the contribution of the sediment yield from the drainage basin to the sediment load of the trunk river is limited. (b) Although a large quantity of water was extracted from the river mouth reach in recent years, relative to the huge water flow of the mainstream of the river $\left(896.4 \times 10^{9} \mathrm{~m}^{3} / \mathrm{yr}\right.$ in $\left.1950-2010\right)$, the volume of water extracted comprises only a small proportion of the total and therefore has a minimal impact on sediment load. (c) Sand mining appeared to play a more important role in shaping the river course than reduction of the sediment load. Overall, the regulatory effect of the river mouth reach is very limited. These results indicate that this large river has great potential to accommodate disturbances of the river mouth reach from the local drainage basins.

5.2. Impacts of the TGD. Previous studies demonstrated that the TGD has significant impacts on the hydrological regime of the middle and lower reaches. However, its effects on the river mouth reach have not been fully addressed. In the present study, we found that the TGD also had significant impacts on the sediment process in the river mouth reach. Before impoundment of the TGD, the average deposition rate in the study area was $3.07 \mathrm{Mt} / \mathrm{yr}$; however, the deposition increased to $29.90 \mathrm{Mt} / \mathrm{yr}$ after impoundment. Since there were no significant changes in the physical conditions of the river channel and the local drainage basin, this change was mainly due to the impacts of the TGD. It is believed that this increasing deposition was due to the coarsening of the suspended load caused by erosion in the middle reaches of the Yangtze River [31].

Erosion will generally occur below a dam. In the Yangtze River, the severity of erosion increases with proximity to the TGD [10]. The study area is located $1149 \mathrm{~km}$ away from the TGD, and erosion does not appear to have extended to the study area during the first ten years of operation (2003-2012). Accordingly, more time may be needed for the impacts of the TGD to fully manifest. The responses of the river channel of the river mouth reach might be very complicated because of the length and the large body of the river channel.

5.3. Limitations of the Results of the Present Study. A large dataset was compiled to facilitate the investigation; however, these data originate from a variety of sources and have different reliabilities, which might lead to the uncertainty associated with the results presented herein. Nevertheless, the hydrological data used in this study were obtained from the Ministry of the Water Resources of China and underwent strict examinations before being released [32]. In the present study, only suspended load was applied in the discussion. A previous study showed that the bed load comprised a very small proportion of the total load in the Yangtze River [32]. Accordingly, the error associated with these data as well as the estimations based on these data is likely minimal.

The main uncertainties in the present study are likely related to errors in results calculated based on the relief maps and the estimated volume of sand mining, which both may have had significant impacts on studies of changes in the river channel.

In this study, we reviewed the findings of Wang et al. [16], Liu [15], and Qu [17] and applied their results to build a sediment budget for the river mouth reach. However, it is important to note that the results of these studies are quite different. We thought that these differences could be attributed to errors associated with the process used for depth measurement and digital elevation model (DEM) building (Figure 3). Errors could exist in each step in the above processes, and consequently bring uncertainty to the results. Specifically, for determination of the depth, the error might exist in the precision of the bathymetric point in different measurement times, the accuracy of the depth measurement, and the density of the bathymetric point. For DEM building, the error might exist in the methodologies, or the control points and boundary conditions. The studies conducted by Wang et al. [16], Liu [15], and Qu [17] are all based on relief maps of the river channel that were generated by government agencies. However, these relief maps were developed for navigation and 


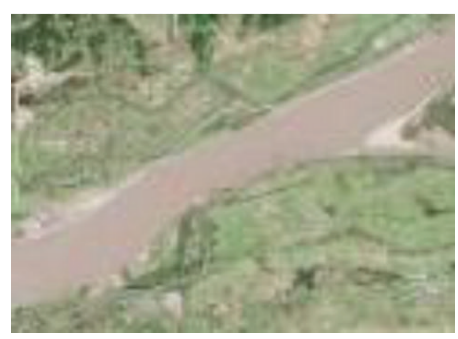

(a)

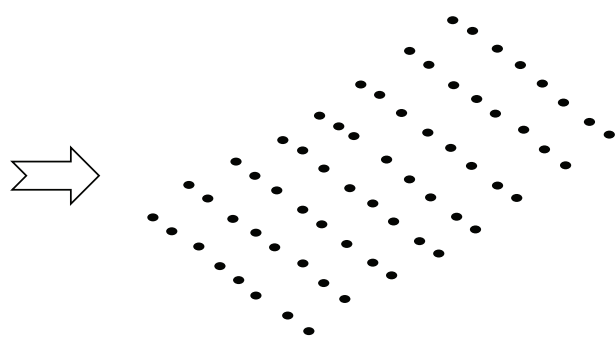

(b)
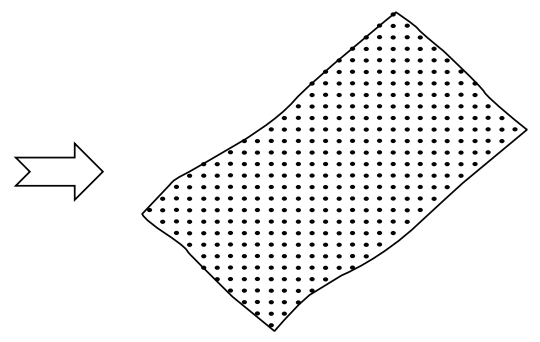

(c)

FIgURE 3: The processes of depth measurement and DEM building of the river channel. (a) River course; (b) cross section measurement (dots are bathymetric points); (c) grid DEM data.

their applicability to river channel mapping has not yet been addressed. In view of this uncertainty, we thought that the differences of the studies of Wang et al. [16], Liu [15], and $\mathrm{Qu}$ [17] might be attributed to the careless applications of the relief maps. Further studies are needed to address these issues.

\section{Conclusions}

This study investigated sediment issues at the river mouth reach of the Yangtze River. The results presented herein enable quantitative estimation of the contribution of the river mouth reach to the sediment load of the Yangtze River. From 1965 to 2002, sediment discharge into the river mouth reach of the Yangtze River was $7.54 \mathrm{Mt} / \mathrm{yr}$ from the local tributaries and the adjacent Huaihe River, which is much lower than its proportion in terms of its length and drainage area. When the impacts of sand mining and water extraction were considered, a total loss of $1.78 \mathrm{Mt} / \mathrm{yr}$ occurred during this period. This sediment loss was very low relative to the large body of the studied river course $(417 \mathrm{~km}$ in length and $1-10 \mathrm{~km}$ in width) and was below our expectations.

After impoundment of the TGD, downstream sediment recovery below the TGD was limited to the middle and lower reaches. In the river mouth reach, deposition occurred after impoundment $(29.90 \mathrm{Mt} / \mathrm{yr}$, including the impact of sand mining). When combined with the sediment from local tributaries and the Huaihe River, as well as sediment loss because of water extraction, a net loss of $30.89 \mathrm{Mt} / \mathrm{yr}$ (about $21.3 \%$ of the sediment load at Datong at the same time) of sediment load occurs in the river mouth reach. The river mouth reach has acted as a sink, but not a source, since impoundment, which exacerbates the decrease of sediment discharge into the sea.

We also found that uncertainties exist in examination of the sediment processes due to insufficient datasets, as well as defects in the methodologies used to calculate changes in the channel. Additional studies should be conducted to improve measurements of changes in both river channel morphology and water and sediment discharges at the river mouth reach.

\section{Conflict of Interests}

The authors declare that there is no conflict of interests regarding the publication of this paper.

\section{Acknowledgments}

This study was supported by the Natural Science Foundation of China (41001301, 412014015), Anhui Provincial Natural Science Foundation of China (1408085MD77), Foundation of State Key Laboratory of Soil Erosion and Dry land Farming on the Loess Plateau (K318009902-1319, 10501-1217), and the Natural Science Foundation of Education Bureau of Anhui Province (KJ2013Z246). Two anonymous reviewers are thanked for their valuable comments and suggestions.

\section{References}

[1] D. E. Walling and D. Fang, "Recent trends in the suspended sediment loads of the world's rivers," Global and Planetary Change, vol. 39, no. 1-2, pp. 111-126, 2003.

[2] S. B. Dai and X. X. Lu, "Sediment load change in the Yangtze River (Changjiang): a review," Geomorphology, vol. 215, pp. 6073, 2014.

[3] C. Nilsson, C. A. Reidy, M. Dynesius, and C. Revenga, "Fragmentation and flow regulation of the world's large river systems," Science, vol. 308, no. 5720, pp. 405-408, 2005.

[4] O. E. Frihy, K. M. Dewidar, and M. M. El Banna, "Natural and human impact on the northeastern Nile delta coast of Egypt," Journal of Coastal Research, vol. 14, no. 3, pp. 1109-1118, 1998.

[5] J. P. M. Syvitski, C. J. Vörösmarty, A. J. Kettner, and P. Green, "Sinking deltas due to human activities," Nature Geoscience, vol. 2, pp. 681-686, 2009.

[6] S. L. Yang, J. D. Milliman, P. Li, and K. Xu, “50,000 dams later: erosion of the Yangtze River and its delta," Global and Planetary Change, vol. 75, no. 1-2, pp. 14-20, 2011.

[7] X. K. Yang and X. X. Lu, "Estimate of cumulative sediment trapping by multiple reservoirs in large river basins: an example of the Yangtze River basin," Geomorphology, no. 227, pp. 49-59, 2014.

[8] X. Li, Y. X. Zhou, L. P. Zhang, and R. Y. Kuang, "Shoreline change of Chongming Dongtan and response to river sediment load: a remote sensing assessment," Journal of Hydrology, vol. 511, pp. 432-442, 2014.

[9] X. Lai, J. Jiang, G. Yang, and X. X. Lu, "Should the Three Gorges Dam be blamed for the extremely low water levels in the middlelower Yangtze River?" Hydrological Processes, vol. 28, no. 1, pp. 150-160, 2014.

[10] Z. J. Dai and J. T. Liu, "Impacts of large dams on downstream fluvial sedimentation: an example of the Three Gorges Dam (TGD) 
on the Changjiang (Yangtze River)," Journal of Hydrology, vol. 480, pp. 10-18, 2013.

[11] S. L. Yang, J. Zhang, S. B. Dai, M. Li, and X. J. Xu, "Effect of deposition and erosion within the main river channel and large lakes on sediment delivery to the estuary of the Yangtze River," Journal of Geophysical Research F: Earth Surface, vol. 112, no. 2, Article ID F02005, 2007.

[12] X. G. Wu, “The sediments and evolution of Taihu Lake," Journal of Lake Sciences, vol. 4, no. 3, pp. 54-60, 1992 (Chinese).

[13] G. X. Hong and G. M. Han, "An analysis on the sediment load discharging into and out of the Hongzehu Lake," Water Conservancy Science and Technology and Economy, vol. 13, no. 4, pp. 240-241, 2007 (Chinese).

[14] B.-Y. Yu and Y.-S. Yu, "Sediment deposition in Hongze Lake," Journal of Sediment Research, no. 6, pp. 36-41, 2010 (Chinese).

[15] D. F. Liu, "An analysis on the erosion and deposition of the channel of the Yangtze River in Anhui section," Jianghuai Water Resources Science and Technology, no. 6, pp. 26-28, 2013 (Chinese).

[16] J. Wang, P. Liu, Z. R. Gao, S. B. Bao, G. J. Cao, and G. X. Qu, "Temporal-spatial variation of the channel in Jiangsu reach of the Yangtze River during the last 44 years," Acta Geographica Sinica, vol. 62, no. 11, pp. 1185-1193, 2007 (Chinese).

[17] G. X. Qu, The Characteristics and Explanations of Channel Change in the Datong-Jiangyin Reach of the Lower Yangtze River: 1959-2008, Nanjing Normal University, Nanjing, China, 2014.

[18] Q. Wang and J. Y. Chen, "Formation and evolution of hongze lake and the huaihe river mouth along the lake," Journal of Lake Science, vol. 11, no. 3, pp. 237-244, 1999 (Chinese).

[19] D. E. Walling and A. L. Collins, "The catchment sediment budget as a management tool," Environmental Science and Policy, vol. 11, no. 2, pp. 136-143, 2008.

[20] S. L. Yang, "Discussion on contribution of water and sediment fluxes to sea from sub-catchment below Datong Station of Yangtze River," Journal of Yangtze River Scientific Research Institute, vol. 3, no. 44, pp. 13-15, 2013.

[21] H. F. Yin, G. J. Chen, and C. A. Li, "Sediment deposition issues of the middle Yangtze River," Science of China: Series D, vol. 34, no. 3, pp. 195-209, 2004.

[22] S.-B. Dai, S.-L. Yang, J. Zhu, A. Gao, and P. Li, “The role of Lake Dongting in regulating the sediment budget of the Yangtze River," Hydrology and Earth System Sciences, vol. 9, no. 6, pp. 692-698, 2005.

[23] S. L. Yang, J. D. Milliman, K. H. Xu, B. Deng, X. Y. Zhang, and X. X. Luo, "Downstream sedimentary and geomorphic impacts of the Three Gorges Dam on the Yangtze River," Earth-Science Reviews, vol. 138, pp. 469-486, 2014.

[24] MWR, Bulletin of China River Sediment, Press of Ministry of Water Resources of the People's Republic of China, 2008, http:// www.cjh.com.cn/.

[25] E. F. Zhang and X. Q. Chen, "Changes of water discharge between Datong and the Changjiang Estuary during the dry season," Acta Geographica Sinica, vol. 58, no. 2, pp. 231-238, 2003.

[26] C. Xiqing, Z. Erfeng, M. Hongqiang, and Y. Zong, "A preliminary analysis of human impacts on sediment discharges from the Yangtze, China, into the sea," Journal of Coastal Research, vol. 21, no. 3, pp. 515-521, 2005.

[27] J.-Q. Mao, "Numerical simulation study of flow field around the sandpit with complicate shape in riverbed," Advances in Water Science, vol. 15, no. 1, pp. 6-10, 2004 (Chinese).
[28] Y. Mao and C. A. Huang, "Experimental study on effect of sand mining on riverbed deformation," Shuili Xuebao, no. 5, pp. 6469, 2005 (Chinese).

[29] S. B. Dai and S. L. Yang, "The impacts of sand mining on the sediment load of the Yangtze River," Shanghai Geology, no. 1, pp. 17-20, 2004 (Chinese).

[30] S. B. Dai, X. X. Lu, S. L. Yang, and A. M. Cai, "A preliminary estimate of human and natural contribution to the sediment decline from the Yangtze River to the East China Sea," Quaternary International, vol. 186, pp. 43-54, 2008.

[31] X. X. Luo, S. L. Yang, and J. Zhang, "The impact of the Three Gorges Dam on the downstream distribution and texture of sediments along the middle and lower Yangtze River (Changjiang) and its estuary, and subsequent sediment dispersal in the East China Sea," Geomorphology, vol. 179, pp. 126-140, 2012.

[32] Z. Y. Wang, Y. Li, and Y. He, "Sediment budget of the Yangtze River," Water Resource Research, vol. 43, Article ID W04401, 2007. 

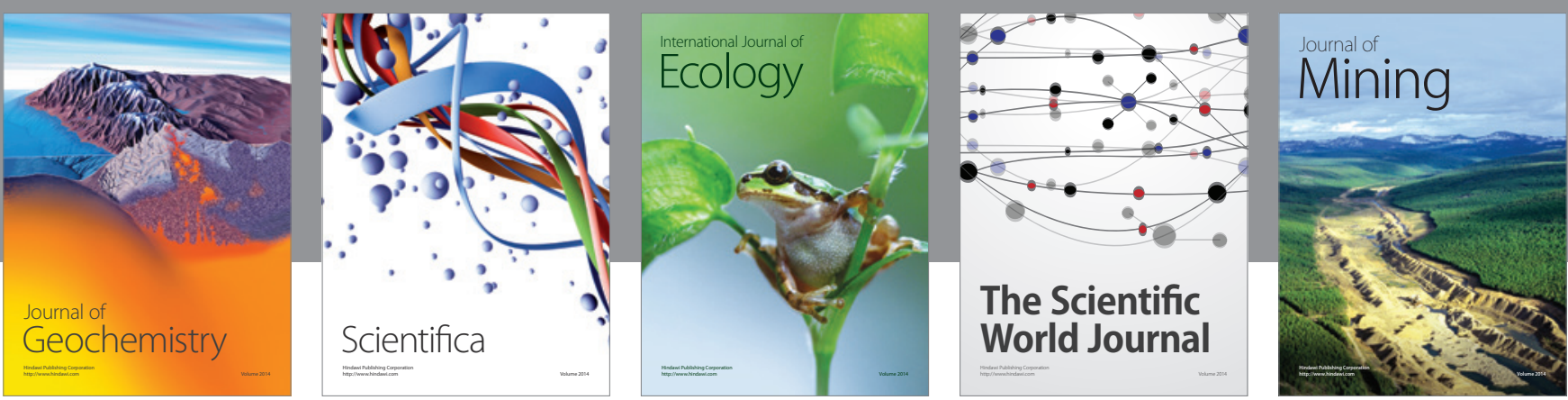

The Scientific World Journal
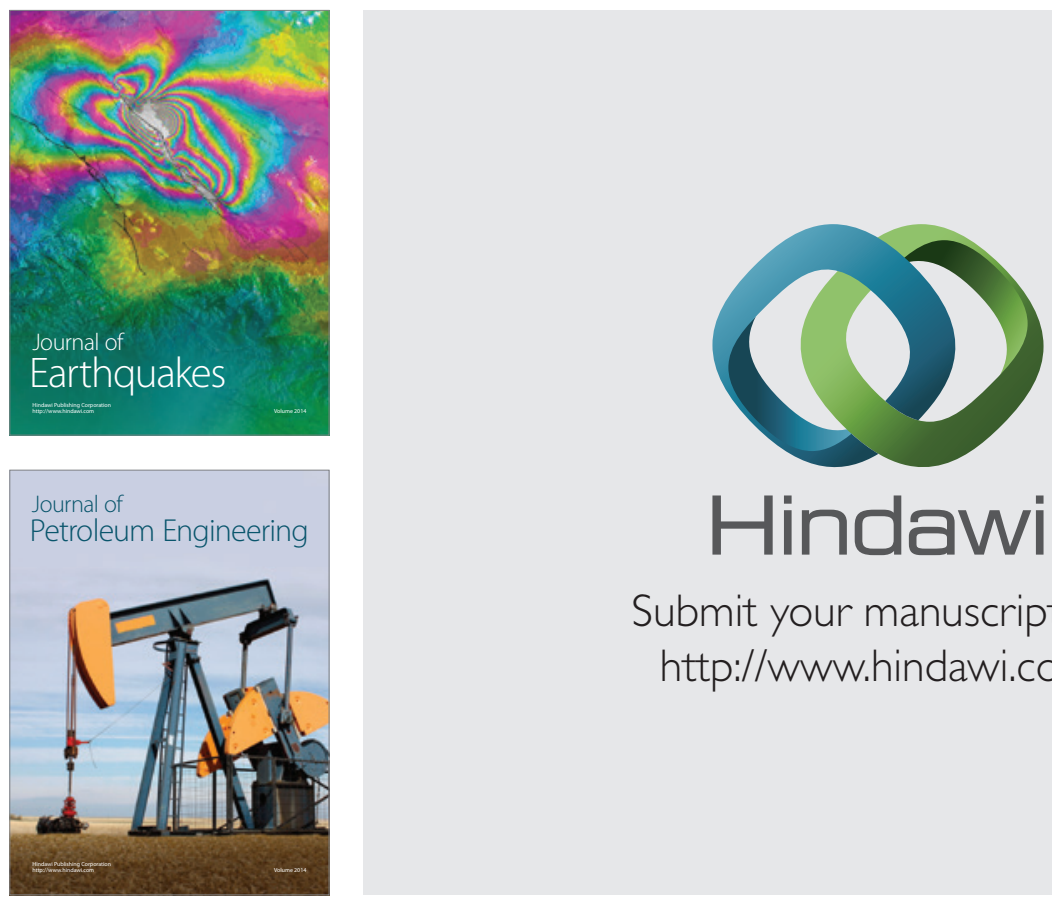

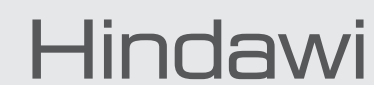

Submit your manuscripts at

http://www.hindawi.com
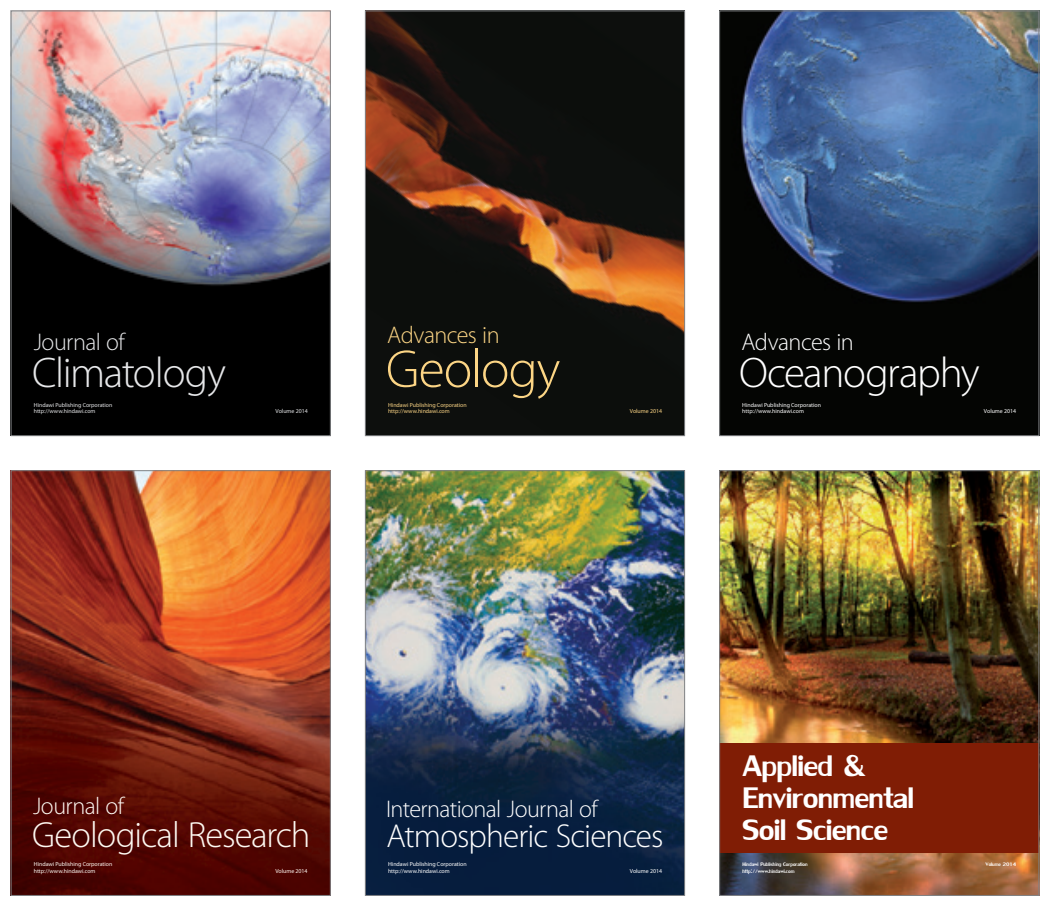
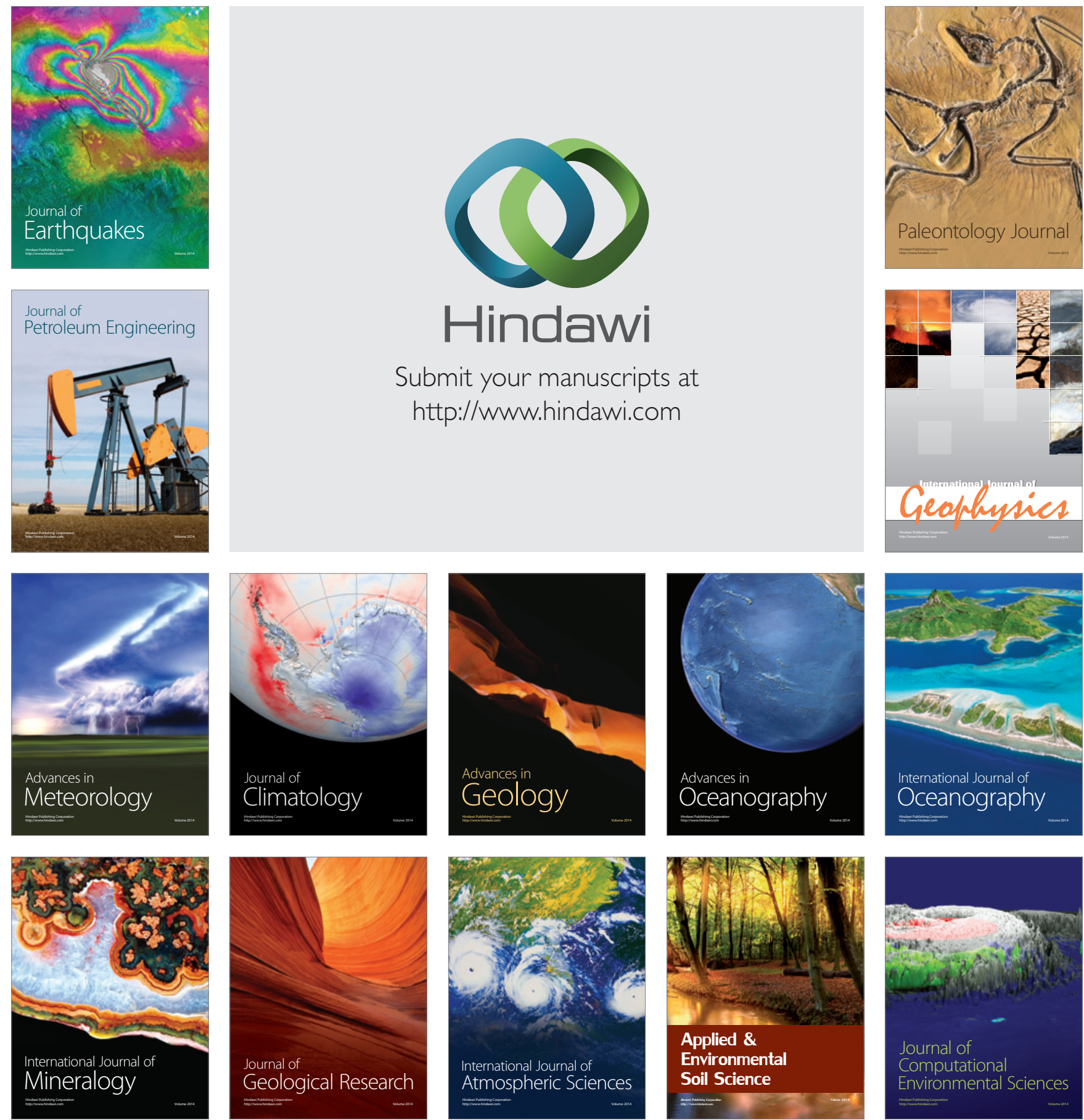